\title{
Who is at higher risk of hypertension? Socioeconomic status differences in blood pressure among Polish adolescents: a population-based ADOPOLNOR study
}

\author{
Maria Kaczmarek $^{1}$ • Barbara Stawińska-Witoszyńska ${ }^{2}$ Alicja Krzyżaniak ${ }^{2}$. \\ Malgorzata Krzywińska-Wiewiorowska ${ }^{2} \cdot$ Aldona Siwińska $^{3}$
}

Received: 14 January 2015 /Revised: 21 April 2015 / Accepted: 23 April 2015 / Published online: 9 May 2015

(C) The Author(s) 2015. This article is published with open access at Springerlink.com

\begin{abstract}
In Poland, there is no data on parental socioeconomic status (SES) as a potent risk factor in adolescent elevated blood pressure, although social differences in somatic growth and maturation of children and adolescents have been recorded since the 1980s. This study aimed to evaluate the association between parental SES and blood pressure levels of their adolescent offspring. A cross-sectional survey was carried out between 2009 and 2010 on a sample of 4941 students ( 2451 boys and 2490 girls) aged 10-18, participants in the ADOPOLNOR study. The depended outcome variable was the level of blood pressure (optimal, pre- and
\end{abstract}

Communicated by Peter de Winter

Revisions received: 18 March 2015/21 April 2015

Maria Kaczmarek

makac@amu.edu.pl

Barbara Stawińska-Witoszyńska

epidemiologia@ump.edu.pl

Alicja Krzyżaniak

akrzyzan@amp.poznan.pl

Małgorzata Krzywińska-Wiewiorowska

epidemiologia@ump.edu.pl

Aldona Siwińska

pedgastro@skp.ump.edu.pl

1 Department of Human Biological Development, Institute of Anthropology, Faculty of Biology, Adam Mickiewicz University in Poznań, Umultowska 89, 61-614 Poznań, Poland

2 Department of Epidemiology, Chair of Social Medicine, Poznań University of Medical Sciences, Poznań, Poland

3 Department of Pediatric Cardiology and Nephrology, Poznań University of Medical Sciences, Poznań, Poland hypertension) and explanatory variables included place of residence and indicators of parental SES: family size, parental educational attainments and occupation status, income adequacy and family wealth. The final selected model of the multiple multinomial logistic regression analysis (MLRA) with backward elimination procedure revealed the multifactorial dependency of blood pressure levels on maternal educational attainment, paternal occupation and income adequacy interrelated to urbanization category of the place of residence after controlling for family history of hypertension, an adolescent's sex, age and weight status. Consistent rural-to-urban and socioeconomic gradients were found in prevalence of elevated blood pressure, which increased with continuous lines from large cities through small- to medium-sized cities to villages and from high-SES to low-SES familial environments. The adjusted likelihood of developing systolic and diastolic hypertension decreased with each step increase in maternal educational attainment and increased urbanization category. The likelihood of developing prehypertension decreased with increased urbanization category, maternal education, paternal employment status and income adequacy. Weight status appeared to be the strongest confounder of adolescent blood pressure level and, at the same time, a mediator between their blood pressure and parental SES.

Conclusion: The findings of the present study confirmed socioeconomic disparities in blood pressure levels among adolescents. This calls for regularly performed blood pressure assessment and monitoring in the adolescent population. It is recommended to focus on obesity prevention and socioeconomic health inequalities by further trying to improve living and working conditions in adverse rural environments. 
What is known:

- Socioeconomic gradient exists in adolescent blood pressure levels.

- Adolescents from lower SES families are at greater risk of hypertension.

What is new:

- Urbanization levels of residence area affect adolescent blood pressure by parental socioeconomic status.

- Socioeconomic inequalities in adolescent hypertension may be modulated through effects of body weight.

Keywords Adolescence - Systolic blood pressure - Diastolic blood pressure $\cdot$ Place of residence $\cdot$ Parental education and occupation · Income adequacy $\cdot$ Family size $\cdot$ BMI

$\begin{array}{ll}\text { Abbreviations } \\ \text { BMI } & \text { Body mass index } \\ \text { BP } & \text { Arterial blood pressure } \\ \text { CI } & \text { Confidence interval } \\ \text { DBP } & \text { Diastolic blood pressure } \\ \text { FAS II } & \text { Family Affluence Scale II } \\ \text { FHH } & \text { Family history of hypertension } \\ \text { GP } & \text { General practitioner } \\ \text { GPM } & \text { Gneupel Precision Mechanics } \\ \text { HTN } & \text { Hypertension } \\ \text { Intra- } & \text { Intra-observer technical error } \\ \text { TEM } & \\ \text { Inter- } & \text { Inter-observer technical error } \\ \text { TEM } & \\ \text { IOTF } & \text { International Obesity Task Force } \\ \text { MCA } & \text { Multiple correspondence analysis } \\ \text { MLRA } & \text { Multiple multinomial logistic regression } \\ & \text { analysis } \\ \text { OR } & \text { Odds ratio } \\ \text { Pre-HTN } & \text { Prehypertension } \\ \text { SBP } & \text { Systolic blood pressure } \\ \text { SES } & \text { Socioeconomic status } \\ \end{array}$

\section{Introduction}

The rate of diagnosis and prevalence of hypertension (HTN) in children and adolescents appear to show a steady upward trend. Recent reports have shown that prevalence of primary hypertension in the under- 18 population varies from 5 to $20 \%$ worldwide $[27,38,84]$ and from 5 to $12 \%$ in Poland $[58,60,76]$.

Persistent elevation of arterial blood pressure (BP) is an independent risk factor for myocardial infarction and heart failure, stroke and end-stage renal disease. Hypertension and specific morbid sequelae have emerged as leading causes of premature death among adults worldwide [1]. Although it is rare for the young to develop atherosclerotic cardiovascular disease (CVD), the cumulative long-term effects of high BP may have multiple acute and chronic complications. There is evidence that high BP in young age is associated with early markers of cardiovascular abnormalities such as left ventricular hypertrophy and atherosclerosis [3, 6, 28]. Comorbid conditions include obesity, high blood lipid levels, learning and attention problems and type 2 diabetes $[2,13]$. However, the main complication of persistent high blood pressure in young age is its progress to adulthood, making it the greatest cardiovascular disease risk [4]. Several lines of evidence suggest that young people who enter adulthood with higher BP parameters are more likely than their normotensive peers to be affected with HTN and its morbidity sequelae [19, 36]. Thus, earlier stages of life seem to be critical to HTN [20].

Hypertension is a common condition of multifactorial determination. It is suggested that HTN develops from a complex interplay of genetic, developmental, environmental and behavioural factors $[38,57,61]$. Heredity is a predisposing factor; almost half of young people with primary HTN have a positive family history of this condition, but environmental and individual contextual conditions may also play an important role in the development of $\operatorname{HTN}[61,67]$. A number of factors have been identified as predictors of elevated blood pressure in children and adolescents. They include maternal, birth and early-life characteristics, such as maternal weight status (BMI), smoking during pregnancy, low birth weight, breast feeding duration and childhood obesity [65, 70, 84]. Life cycle approach indicates that adolescence and especially puberty is a critical stage for adult BP. Longitudinal data showed that during puberty, BP may increase more than before it [81]. Rate of change in BP is likely to be synchronized with rapid somatic growth and adolescent growth spurt in height and weight $[81,86]$. Moreover, changes in stature during puberty are closely linked to Tanner staging for sexual maturation. Gonadal hormones with possibly a preponderant effect of testosterone may affect BP levels and emergence of BP sexual dimorphism well manifest in adulthood [17, 29]. Additionally, adolescence is marked by increasing involvement in health risk behaviours often continuing into adult life [32]. Unfavourable effects of sedentary lifestyle, lack of vigorous or moderate physical activity, obesity, lack of a proper nutritionally balanced diet, high salt intake, low potassium and low calcium intake, tobacco use, alcohol intake and high stress may increase the risk for the development of adolescent hypertension $[62,63]$. Furthermore, many of these factors are additive, such as unhealthy diet, insufficient physical activity and obesity, and vary in their propensity to contribute to the elevation of BP.

The literature on the potential confounders and mediators of childhood and adolescent hypertension has emphasized the role family level of socioeconomic status (SES) plays in the development of this condition $[15,55]$. The association between parental SES and their offspring's health outcomes has 
been well established $[5,16,25]$. These studies suggest that children of low-SES families are likely to have worse health outcomes. They are at a higher risk of CVD, elevated BP, metabolic syndrome, greater BMI and other negative health outcomes $[43,45]$. They are also more likely to engage in riskfor-health behaviours than their better-off peers [34, 52]. Unlike heredity, ethnicity and geographic location, parental SES and adolescents' behavioural factors are potentially modifiable. Elucidating the pathways by which these factors influence BP levels and health consequences (ischemic heart disease, stroke and others) may help in understanding the health gaps between different social groups and in developing a public health programme to counteract the health inequality [41].

In Poland, there is no data available for parental SES as a potent risk factor in adolescent hypertension, although social differences in somatic growth, development and maturation have been recorded since the 1980s [8, 10, 9]. This study aimed to fill that knowledge gap by focusing on SES differences in blood pressure (BP) levels among Polish adolescents 10-18 years old. The specific aims for this study were (i) to calculate prevalence of elevated blood pressure in relation to selected indicators of parental SES and (ii) to establish relative importance of SES-related factors on the development of high blood pressure. The study hypothesis was that adolescents living in low-SES families might be at a higher relative risk of elevated BP than their better-off counterparts.

\section{Materials and methods}

Study design and sampling A cross-sectional survey was carried out between February 2009 and September 2010 on a representative, randomly selected sample of adolescents, aged 10-18 years, participants in the ADOPOLNOR project, a transdisciplinary study on adolescent health and quality of life. It was an ethnically homogeneous group of students in grades 5 through 6 of primary school, 1 through 3 of junior secondary and 1 to 2 of senior secondary schools in the Wielkopolska province and its capital, the city of Poznań.

Sample size was calculated using the formula for quantitative variable and a single cross-sectional survey [66]. The number of selected subjects was 5400 .

Sampling procedure was a stratified two-stage cluster sample design. For the first sampling stage, schools were sampled from the sampling frame provided by the Ministry of Education for the Wielkopolska province via the Poznan Board of Education. Sampling was stratified by rural and urban areas as provided by Rogacki [79] and Central Statistical Office of Poland 2008 (www.stat.gov.pl). In this way, 52 schools were selected. The second sampling stage consisted of the selection of classes from the target grade of each participating school. In this procedure, if the number of classes was more than one, the class was randomly selected (as, for example, one class out of every six). In most villages, however, the students were assigned to only one class of each year level group.

The study design and study protocol were approved by the Bioethics Commission of the Poznań University of Medical Sciences (Resolution no. 311/07) and the Poznań Board of Education (Resolution WAF-405/1/JM/07). The survey was carried out in compliance with principles outlined in the Helsinki Declaration and subsequent amendments [90]. Schools' headmasters received an invitation letter and an information brochure about the research project. They approved the study protocol and gave permission to run the study in their schools. Furthermore, in collaboration with them, subjects' parents were informed about the goals of the study and possibility of refusing the participation of their children in the study. Enrolled for the study were those students whose parents had given a written consent for them to participate. In addition, students who had attained the legal age for consent (16 years in Poland) gave assent for their participation in the study. Almost all parents $(97.1 \%)$ provided written informed consent for their children to participate in the ADOPOLNOR research project and $96.7 \%$ of young people aged between 16 and 18 gave us their written consent to be participants of the study.

Complete data on parental characteristics (demographic, socioeconomic, behavioural) and adolescent characteristics at time of investigation (medical examination, anthropometry, arterial blood pressure and physical fitness) were obtained for 2451 male and 2490 female students, the total of 4941.

All examinations were performed in school nursery rooms during morning hours (up to noon). The study protocol included medical examination, anthropometric measurements, and parental and self-reported background data questionnaires. Detailed description of the ADOPOLNOR study is available elsewhere [51].

General health status Health status of each subject was assessed by general practitioners (GPs) during general medical examinations, via self-report and proxy reports from parents.

Anthropometric measurements Body height and weight were measured by well-trained researchers according to standard procedures [56]. The subject, wearing light gym exercise clothes and without shoes, was standing in an upright position with heels together, arms to the side, legs straight, shoulders relaxed and the head positioned in the Frankfurt plane. The height was measured with a portable Swiss-made Gneupel Precision Mechanics (GPM) anthropometer to the nearest $1 \mathrm{~mm}$ from the highest point on the midline vault (vertex) to the floor a subject was standing on. Body weight was measured to the nearest $0.1 \mathrm{~kg}$ on a calibrated electronic scale (Precision Health Scale). Then, BMI was calculated by taking a subject's weight $(\mathrm{kg})$ and dividing it by his/her height squared $\left(\mathrm{m}^{2}\right)$. Following 
the IOTF recommendation, Cole's cutoff values were used to determine the weight status [23, 24].

Chronological age was calculated in decimal values by subtracting the date of examination from the date of birth. The age groups were divided by years, defined in terms of the whole year; e.g., 10 years old group involved subjects between 10.00 and 10.99 years old.

Blood pressure measurements Blood pressure was measured by school nurses strictly following the guidelines of the Fourth Protocol of the American Working Group of High Blood Pressure in Children and Adolescents [74]. A fully calibrated TECH MED TM-Z mercury gauge sphygmomanometer with sets of exchangeable cuffs and a clinical stethoscope was used for all BP measurements.

Blood pressure, systolic and diastolic, was measured in duplicate on each of the three occasions separated by a 2day interval. Measurements were taken on the right arm with the subjects sitting for at least a 5-min rest, and the average of the two measurements was the final result for the given day as it was suggested in the Seventh Report for adults [22]. The systolic and diastolic BP measurements corresponded to the reading on the sphygmomanometer at the first and fifth phases of the Korotkoff sounds, respectively. The scale on the sphygmomanometer was graduated in 2-mmHg divisions. The readings were made to the nearest millimeter Hg. Calculated intraobserver technical error (intra-TEM) equalled $1.3 \mathrm{mmHg}$ and inter-observer technical error (inter-TEM) equalled $2.3 \mathrm{mmHg}$ [59]. The BP classification was determined using the surveillance method. For each participant, the mean of measurements taken on three occasions was calculated. The values of mean systolic blood pressure (SBP) and diastolic blood pressure (DBP) were adjusted by sex, age and height percentile using current reference data for Polish children and adolescents [59]. Normal BP was defined as systolic and diastolic BP less than 90th percentile, prehypertension (high normal BP) was defined as an average systolic or diastolic BP of greater than or equal to 90th percentile but less than 95th percentile, and hypertension was defined as an average systolic or diastolic $\mathrm{BP}$ of greater than or equal to 95th percentile [39].

Socioeconomic status Socioeconomic status was assessed through a self-reported family wealth using the Family Affluence Scale II (FAS II) and reports from parents using the ADOPOLNOR-R survey instrument. The SES indicators used in the study were the place of residence categorized according to the urbanization level (village with population of less than 1000 inhabitants, mainly engaged in farm work and this work is a source of income, small- to medium-sized city with population of less than 100,000 , large-sized city with a population of 100,000 or more) [79], paternal and maternal educational attainment (the number of years of schooling completed and equalled to educational level: less than
12 years $=$ primary $/$ vocational level, 12 years $=$ secondary level, more than 12 years=third level) and occupation status, family size (number of children in family), family financerelated burden referred to as income adequacy indicative of the objective financial situation, dwelling conditions and others (rated as an ordinal measure of more than enough, just enough or not enough money to cover expenses each month reported by study participants' parents).

The FAS II, a four-item measure of family wealth, provided by students, was reported by number of cars in family, asking if the respondent have one's own bedroom, number of family's vacation travels during the past 12 months and number of computers in the household. The FAS II total score could range from 0 to 9 , with higher scores indicating higher level of family wealth. In the study, it was scored as a composite score and classified into three categories: low affluence (0-2), middle affluence (3-5) and high affluence (6-9).

Data analysis The outcome of interest was demographic and parental socioeconomic factors associated with BP status $(0=$ normotension, $1=$ prehypertension and $2=$ hypertension) in adolescent males and females after controlling for parental hypertension, sex, age and weight status. At first, multiple correspondence analysis (MCA) was used to determine whether the explanatory variables for the BP status were associated to each other and which of them might potentially operate in an additive way [85]. Crude associations of BP status and all potential covariate variables were evaluated individually using the chi-square Pearson test. Multiple multinomial logistic regression analyses (MLRA) were used to assess the association between BP status and the variables in question. The dependent outcome variable was a dichotomous variable of BP status. Two models were evaluated: model 1 involving normotensive vs. prehypertensive BP status and model 2 involving normotensive vs. hypertensive status after adjustment for all potentially confounding variables simultaneously. The odds ratio was used as a measure of association. A final explanatory model with a subset and relative odds ratio (OR) of the factors associated with BP status was obtained using a stepwise procedure with backward elimination and rejection criterion of the $p$ value greater than 0.05 .

Statistical analyses were performed using the STAT ISTICA 10.0 data analysis software system (StatSoft Inc. Tulsa, OK, USA). All significance tests comprised two-way determinations. A value of $p<0.05$ was considered statistically significant.

\section{Results}

The social background of the sample is shown in Table 1.

The majority of families were urban residents $(61.7 \%)$ of working parents ( $60.7 \%$ for both parents combined), fathers 
Table 1 Characteristics of study participants on family history of hypertension, weight status and indicators of parental SES

\begin{tabular}{|c|c|}
\hline Variables & $\begin{array}{l}N=4941 \\
n(\%)\end{array}$ \\
\hline Family history of hypertension ${ }^{\mathrm{a}}$ & $1018(20.6)$ \\
\hline \multicolumn{2}{|l|}{ Weight status-BMI $\left(\mathrm{kg} / \mathrm{m}^{2}\right)$} \\
\hline Underweight & $534(10.8)$ \\
\hline Normal weight & $3548(71.8)$ \\
\hline Overweight & $697(14.1)$ \\
\hline Obesity & $162(3.3)$ \\
\hline \multicolumn{2}{|l|}{ Place of residence } \\
\hline Rural areas & $1897(38.3)$ \\
\hline Urban areas $<100,000$ inhabitants & $2021(40.9)$ \\
\hline Urban areas $\geq 100,000$ inhabitants & $1023(20.8)$ \\
\hline \multicolumn{2}{|l|}{ Paternal education } \\
\hline$<12$ years (primary, vocational) & $2658(53.8)$ \\
\hline 12 years (secondary) & $1603(32.5)$ \\
\hline$>12$ years (university degree or above) & $680(13.7)$ \\
\hline \multicolumn{2}{|l|}{ Maternal education } \\
\hline$<12$ years (primary, vocational) & $1947(39.4)$ \\
\hline 12 years (secondary) & $2013(40.7)$ \\
\hline$>12$ years (university degree or above) & $981(19.9)$ \\
\hline \multicolumn{2}{|l|}{ Paternal occupation } \\
\hline Economically inactive ${ }^{\mathrm{b}}$ & $180(3.6)$ \\
\hline UB/PTJ/pension/others & $513(10.4)$ \\
\hline Employed-full-time job & $2974(60.2)$ \\
\hline Own business & $727(14.7)$ \\
\hline Farming & $547(11.1)$ \\
\hline \multicolumn{2}{|l|}{ Maternal occupation } \\
\hline Economically inactive & $763(15.4)$ \\
\hline UB/PTJ/pension/others & $521(10.5)$ \\
\hline Employed-full-time job & $2849(57.7)$ \\
\hline Own business & $327(6.6)$ \\
\hline Farming & $481(9.8)$ \\
\hline \multicolumn{2}{|l|}{ Number of children in family } \\
\hline 1 child & $752(15.2)$ \\
\hline 2 children & $2312(46.8)$ \\
\hline 3 and more children & $1877(38.0)$ \\
\hline \multicolumn{2}{|l|}{ Income adequacy ${ }^{\mathrm{c}}$} \\
\hline Not enough & $574(11.6)$ \\
\hline Enough & $1832(37.1)$ \\
\hline More than enough & $2535(51.3)$ \\
\hline \multicolumn{2}{|l|}{ Family affluence (FAS II) ${ }^{\mathrm{d}}$} \\
\hline Low & $672(13.6)$ \\
\hline Medium & $2764(55.9)$ \\
\hline High & $1505(30.5)$ \\
\hline
\end{tabular}

UB/PTJ/pension/others unemployment benefits/part-time job/life annuity/all others

${ }^{a}$ First-degree family history of hypertension: maternal and/or paternal hypertension

${ }^{\mathrm{b}}$ A category that includes people who voluntarily remain out of the active workforce, those raising a family at home and/or those who are unemployed

${ }^{c}$ An ordinal measure of more than enough, just enough or not enough money to cover expenses each month reported by study participants' parents

${ }^{\mathrm{d}}$ Family affluence evaluated by adolescent participants in the study having fewer than 12 years of schooling (53.8 \%) and mothers with 12 years of schooling ( $40.7 \%$ ), without financial strain, i.e., with income adequacy $(51.3 \%$ with more than enough income). Family affluence level was self-rated by study participants and the majority of them $(55.9 \%)$ rated it as medium. Families with two children accounted for almost a half of the sample (46.8\%); three and more children $(38.0 \%)$ were next in order of frequency.

Structural relationships among indicators of parental socioeconomic status - explanatory variables in the MCA (data not shown but available upon request from authors) - revealed that rural setting, low parental educational attainment, maternal economic inactivity, large families with three and more children, income inadequacy and low family wealth appeared to cluster closely together. Urban residence $(<100,000$ population) was associated with parental employment, income adequacy, medium family wealth and two children in family. One-child families were related to large city settings $(\geq 100$, 000 population). The high affluent families markedly outlaid from other clusters indicating that the wealth was not associated with a specific setting or parental SES indicator. These associations conform to the pattern of additive nature of urbanization and parental SES factors. The rural-urban disparities in parental SES are shown in Fig. 1. Proportion of parents with low education level was significantly higher for rural areas as it was for income inadequacy and low family wealth (maternal education $<12$ years, 52.8 vs. $29.3 \%$; paternal education $<12$ years, 52.8 vs. $31.2 \%$; income inadequacy 14.8 vs. $10.7 \%$; low family wealth 21.7 vs. $9.9 \%$ for rural and urban settings, respectively). There was also a significant rural vs. urban difference in the adolescent weight status. Prevalence of obese adolescents was higher in rural areas (4 vs. $3 \%)$. Parental hypertension was equally distributed among inhabitants of rural and urban areas.

Table 2 shows the prevalence of BP status (SBP and DBP separately) in the study sample according to potential

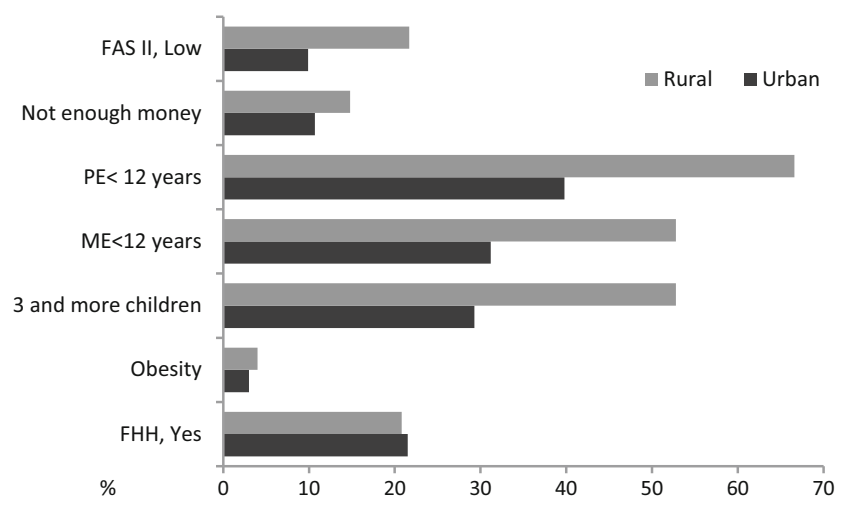

Fig. 1 Rural-to-urban differences in selected indicators of parental socioeconomic status and family history of hypertension. For urban category small, medium and large cities combined. Abbreviations: FAS II Family Affluence Scale II, $P E$ paternal education, $M E$ maternal education, $F H H$ family history of hypertension 
Table 2 Prevalence of prehypertension and hypertension among adolescent students by all factors involved in analysis

\begin{tabular}{|c|c|c|c|c|c|c|c|c|}
\hline \multirow[t]{3}{*}{ Variables } & \multicolumn{8}{|c|}{ Blood pressure level } \\
\hline & \multicolumn{2}{|c|}{ Normal } & \multicolumn{2}{|c|}{ Pre-HTN } & \multicolumn{2}{|l|}{ HTN } & \multicolumn{2}{|l|}{$p$ value } \\
\hline & SBP & DBP & SBP & DBP & SBP & DBP & SBP & DBP \\
\hline Sex & & & & & & & 0.009 & 0.612 \\
\hline Male & 89.9 & 91.3 & 3.5 & 3.5 & 6.6 & 5.2 & & \\
\hline Female & 90.8 & 90.7 & 4.4 & 5.3 & 4.8 & 4.0 & & \\
\hline Age (years) & & & & & & & 0.042 & 0.006 \\
\hline 10 & 90.5 & 92.9 & 3.9 & 3.4 & 5.6 & 3.7 & & \\
\hline 18 & 88.7 & 88.2 & 3.4 & 5.6 & 7.9 & 6.2 & & \\
\hline $\begin{array}{l}\text { Family history } \\
\text { of hypertension }\end{array}$ & & & & & & & $<0.001$ & 0.026 \\
\hline Yes & 84.5 & 88.7 & 5.7 & 5.6 & 9.8 & 5.7 & & \\
\hline No & 92.5 & 92.5 & 4.2 & 4.2 & 3.3 & 3.3 & & \\
\hline Place of residence & & & & & & & $<0.001$ & $<0.001$ \\
\hline Rural areas & 85.3 & 86.0 & 5.7 & 6.8 & 9.0 & 7.2 & & \\
\hline Urban $<100,000$ inhabitants & 90.2 & 91.2 & 4.3 & 3.9 & 5.5 & 4.9 & & \\
\hline Urban $\geq 100,000$ inhabitants & 92.2 & 94.3 & 3.4 & 3.0 & 4.4 & 2.7 & & \\
\hline Paternal education & & & & & & & $<0.001$ & $<0.001$ \\
\hline$<12$ years & 88.5 & 89.1 & 4.5 & 5.1 & 7.0 & 5.8 & & \\
\hline 12 years & 92.1 & 93.4 & 3.4 & 3.9 & 4.5 & 2.7 & & \\
\hline$>12$ years & 93.4 & 95.9 & 3.9 & 2.4 & 2.7 & 1.7 & & \\
\hline Maternal education & & & & & & & 0.002 & $<0.001$ \\
\hline$<12$ years & 88.9 & 87.7 & 3.9 & 6.2 & 7.2 & 6.1 & & \\
\hline 12 years & 90.6 & 93.0 & 4.1 & 3.4 & 5.3 & 3.6 & & \\
\hline$>12$ years & 92.9 & 95.2 & 3.6 & 2.3 & 3.5 & 2.5 & & \\
\hline Paternal occupation & & & & & & & 0.005 & 0.003 \\
\hline Economically active $\mathrm{e}^{\mathrm{a}}$ & 91.3 & 92.7 & 6.0 & 4.3 & 2.7 & 3.0 & & \\
\hline $\mathrm{UB} / \mathrm{PTJ} /$ pension/others & 89.1 & 90.0 & 7.6 & 5.8 & 3.3 & 4.2 & & \\
\hline Economically inactive & 86.1 & 87.4 & 8.2 & 7.3 & 5.7 & 5.3 & & \\
\hline Maternal occupation & & & & & & & 0.04 & $<0.001$ \\
\hline Economically active ${ }^{\mathrm{a}}$ & 94.0 & 94.1 & 4.0 & 3.1 & 2.0 & 2.8 & & \\
\hline $\mathrm{UB} / \mathrm{PTJ} /$ pension/others & 89.1 & 87.9 & 6.6 & 5.1 & 4.3 & 7.0 & & \\
\hline Economically inactive & 86.2 & 84.3 & 7.9 & 8.9 & 5.9 & 6.8 & & \\
\hline Number of children in family & & & & & & & 0.05 & 0.004 \\
\hline 1 child & 91.9 & 93.8 & 3.4 & 2.8 & 4.7 & 3.4 & & \\
\hline 2 children & 90.1 & 92.2 & 3.9 & 3.9 & 6.0 & 3.9 & & \\
\hline 3 and more & 88.5 & 89.4 & 4.3 & 5.4 & 7.2 & 5.2 & & \\
\hline Income adequacy & & & & & & & 0.047 & 0.041 \\
\hline More than enough & 92.5 & 92.5 & 4.1 & 4.0 & 3.4 & 3.5 & & \\
\hline Enough & 89.9 & 89.4 & 5.3 & 5.1 & 4.8 & 5.5 & & \\
\hline Not enough & 88.8 & 90.5 & 5.9 & 4.4 & 5.3 & 5.1 & & \\
\hline Family affluence (FAS II) & & & & & & & 0.532 & 0.151 \\
\hline High & 89.4 & 91.9 & 6.7 & 4.4 & 3.9 & 3.7 & & \\
\hline Low & 89.4 & 89.8 & 7.1 & 5.0 & 3.5 & 5.2 & & \\
\hline Medium & 89.2 & 90.0 & 6.9 & 4.7 & 3.9 & 5.3 & & \\
\hline Weight status-BMI $\left(\mathrm{kg} / \mathrm{m}^{2}\right)$ & & & & & & & $<0.001$ & $<0.001$ \\
\hline Underweight & 97.2 & 96.0 & 2.4 & 2.8 & 0.4 & 1.2 & & \\
\hline Normal weight & 92.3 & 92.9 & 4.4 & 3.8 & 3.3 & 3.3 & & \\
\hline Overweight & 83.0 & 82.9 & 9.1 & 7.7 & 7.9 & 9.4 & & \\
\hline Obesity & 58.2 & 72.1 & 15.1 & 14.3 & 26.7 & 13.6 & & \\
\hline
\end{tabular}

Values are in percentage

${ }^{a}$ Economically active category includes employed/own business/farming 
covariate variables. Crude associations between BP status and covariates are expressed in terms of chi-square test.

In univariate analysis, the SBP levels were associated with all but the family affluence factor. Like systolic, diastolic BP was associated with all but sex and family affluence factors. There was a clear gradient in socioeconomic factors with a tendency of the disadvantage to locate in rural areas, parental low educational attainment, unemployment or farming and in income inadequacy. Higher prevalence of SBP as well as DBP HTN was found for participants with positive family history of hypertension (FHH) (SBP 9.8 vs. $3.3 \%$ and DBP 5.7 vs. $3.3 \%$ for yes and no, respectively) being at older age (7.9 vs. $5.6 \%$ for 18 and 10 years for SBP and 6.2 vs. $3.7 \%$ for DBP) and for male sex (SBP 6.6 vs. $4.8 \%$ ) with obese weight status (SBP 26.7 vs. $3.3 \%$ and DBP 13.6 vs. $3.3 \%$ for obese and normal weight status, respectively), living in rural than urban areas (SBP 9.0 vs. $4.4 \%$ and DBP 7.2 vs. $2.7 \%$ for rural and urban settings, respectively), having parents with low educational attainment (7.0 vs. $2.7 \%$ for SBP and 5.8 vs. $1.7 \%$ for DBP for fathers and 7.2 vs. $3.5 \%$ for SBP and 6.1 vs. $2.5 \%$ for DBP for mothers) and economically inactive (5.7 and $5.9 \%$ for SBP and 5.3 and $6.8 \%$ for DBP for fathers and mothers, respectively) with income inadequacy (5.3\% for SBP and $5.1 \%$ for DBP) as compared to their better-off peers.

At multivariate level, only selected factors remained in their significance. The adjusted odds ratios for parental SES-related risk factors of pre-HTN and HTN after controlling for $\mathrm{FHH}$, sex, age and weight status are presented in Table 3.

The likelihood of developing pre-HTN and HTN among adolescents from families with parental hypertension was almost twice as high as among those from families without $\mathrm{FHH}$ $\left(\mathrm{OR}=1.81,95 \% \mathrm{CI} 1.31 ; 2.51, p_{\text {trend }}=0.0003\right.$ and $\mathrm{OR}=1.72$, $95 \%$ CI $\left.1.34 ; 2.20, p_{\text {trend }}<0.0001\right)$ for SBP and 1.4 times as high for DBP $\left(\mathrm{OR}=1.39,95 \% \mathrm{CI} 1.01 ; 1.91, p_{\text {trend }}=0.039\right.$ and $\left.\mathrm{OR}=1.43,95 \% \mathrm{CI} 1.02 ; 1.99, p_{\text {trend }}=0.036\right)$. Adolescent females were 1.2 times $\left(\mathrm{OR}=1.24,95 \% \mathrm{CI} 1.01 ; 1.54, p_{\text {trend }}=\right.$ $0.039)$ more likely than males to develop systolic pre-HTN and 1.3 times less likely to develop systolic $\mathrm{HTN}(\mathrm{OR}=0.77$; $95 \%$ CI $\left.0.59 ; 0.91, p_{\text {trend }}=0.045\right)$. Adolescents at age 18 as compared to those at age 10 were 2.3 times $(\mathrm{OR}=2.30,95 \%$ CI $\left.2.01 ; 2.97, p_{\text {trend }}=0.005\right)$ and almost 2 times $(\mathrm{OR}=1.72$, $95 \%$ CI $\left.1.05 ; 2.81, p_{\text {trend }}=0.029\right)$ more likely to develop diastolic pre-HTN and HTN. They were 1.2 times $(\mathrm{OR}=$ $1.23,95 \%$ CI $\left.1.06 ; 2.01, p_{\text {trend }}=0.046\right)$ more likely to develop systolic pre-HTN and 1.4 times $(\mathrm{OR}=1.39,95 \%$ CI 1.09; $2.13, p_{\text {trend }}=0.038$ ) more likely to develop systolic HTN.

Residents of large cities were almost twice less likely than their rural counterparts to develop systolic pre-HTN $(\mathrm{OR}=$ $0.56,95 \%$ CI $\left.0.37 ; 0.82, p_{\text {trend }}=0.004\right)$ and systolic HTN $\left(\mathrm{OR}=0.40,95 \%\right.$ CI $\left.0.29 ; 0.55, p_{\text {trend }}<0.0001\right)$. They were almost 4 times less likely to develop diastolic pre-HTN $\left(\mathrm{OR}=0.26,95 \%\right.$ CI 0.17;0.39, $\left.p_{\text {trend }}<0.0001\right)$ and almost 5 times to develop diastolic HTN $(\mathrm{OR}=0.17,95 \%$ CI 0.11 ; $\left.0.27, p_{\text {trend }}<0.0001\right)$.

Compared to adolescents whose mothers had low level of education, peers having mothers with high/academic education level were 1.7 times less likely to develop systolic pre-HTN $\left(\mathrm{OR}=0.60,95 \% \mathrm{CI} 0.48 ; 0.91, p_{\text {trend }}=0.002\right)$ and 1.8 times less likely to develop systolic HTN (OR $=0.54$, $95 \%$ CI $\left.0.39 ; 0.75, p_{\text {trend }}=0.0002\right)$. In addition, they were 2.3 times less likely to develop diastolic pre-HTN (OR= $0.44,95 \%$ CI $\left.0.29 ; 0.66, p_{\text {trend }}<0.0001\right)$ and 2.8 times less likely to develop diastolic HTN (OR=0.36, $95 \%$ CI 0.24 ; $\left.0.55, p_{\text {trend }}<0.0001\right)$.

Paternal occupation and income adequacy were two other factors associated with systolic pre-HTN. Using the employment status as reference category, the adjusted odds ratio for systolic pre-HTN risk from unemployment was $\mathrm{OR}=1.53$ $\left(95 \%\right.$ CI $\left.1.04 ; 2.25, p_{\text {trend }}=0.029\right)$. Using the better-off financial situation (more than enough money) as a reference category, the adjusted odds ratio from income inadequacy for systolic pre-HTN risk was $\mathrm{OR}=1.40\left(95 \% \mathrm{CI} 1.17 ; 1.94, p_{\text {trend }}=\right.$ $0.019)$.

Using the normal BMI for age as reference category, the adjusted odds ratios for systolic pre-HTN and HTN risks from obesity were $\mathrm{OR}=8.42\left(95 \%\right.$ CI $\left.5.33 ; 12.28, p_{\text {trend }}<0.0001\right)$ and $\mathrm{OR}=9.75\left(95 \% \mathrm{CI} 6.91 ; 13 ; 75, p_{\text {trend }}<0.0001\right)$ whereas for diastolic pre-HTN and HTN were OR=3.59 $(95 \% \mathrm{CI}$ $\left.2.28 ; 5.65, p_{\text {trend }}<0.0001\right)$ and $\mathrm{OR}=6.75(95 \% \mathrm{CI} 4.43$; $\left.10.15, p_{\text {trend }}<0.0001\right)$, respectively.

\section{Discussion}

The present study provides the first data documenting social disparities in blood pressure levels among Polish adolescents. The findings revealed the multifactorial dependency of BP levels on geographic, i.e., rural or urban dwelling and SESrelated familial influences at adolescence. The clustering structure of all factors involved in the analysis indicated that residential location might be operating through differential parental SES. The underlying pathways by which parental SES may influence their offspring BP levels include modifiable factors, such as the level of maternal education, status of paternal occupation and income interrelated to urbanization category of the place of residence after adjustment for $\mathrm{FHH}$, subject's sex, age and weight status. Consistent rural-to-urban and socioeconomic gradients were found in prevalence of elevated blood pressure, which increased with continuous lines from large cities through small- to medium-sized cities to villages and from high-SES to low-SES familial environments. Furthermore, the adjusted likelihood of developing HTN decreased with each step increase in maternal educational attainment, and pre-HTN decreased with increased maternal education, paternal employment status and income adequacy. The 
Table 3 Multiple/multinomial logistic regression analysis of most parsimonious set of factors affecting the likelihood of developing prehypertension and hypertension in adolescent students

\begin{tabular}{|c|c|c|c|c|}
\hline \multirow[t]{3}{*}{ Variable } & \multicolumn{4}{|c|}{ Stepwise MLRA with backward elimination } \\
\hline & \multicolumn{2}{|c|}{ Systolic blood pressure } & \multicolumn{2}{|c|}{ Diastolic blood pressure } \\
\hline & $\begin{array}{l}\text { Prehypertension } \\
\text { OR }(95 \% \mathrm{CI})\end{array}$ & $\begin{array}{l}\text { Hypertension } \\
\text { OR }(95 \% \mathrm{CI})\end{array}$ & $\begin{array}{l}\text { Prehypertension } \\
\text { OR }(95 \% \text { CI) }\end{array}$ & $\begin{array}{l}\text { Hypertension } \\
\text { OR (95 \% CI) }\end{array}$ \\
\hline \multicolumn{5}{|l|}{ Sex } \\
\hline Male (reference category) & 1 & 1 & & \\
\hline Female & $1.24(1.01 ; 1.54)$ & $0.77(0.59 ; 0.91)$ & & \\
\hline$p$ value for trend & 0.039 & 0.045 & & \\
\hline \multicolumn{5}{|l|}{ Age (years) } \\
\hline 10 years (reference category) & 1 & 1 & 1 & 1 \\
\hline 18 years & $1.23(1.06 ; 2.01)$ & $1.39(1.09 ; 2.13)$ & $2.30(2.01 ; 2.97)$ & $1.72(1.05 ; 2.81)$ \\
\hline$p$ value for trend & 0.046 & 0.038 & 0.005 & 0.029 \\
\hline \multicolumn{5}{|l|}{ Family history of hypertension } \\
\hline No (reference category) & 1 & 1 & 1 & 1 \\
\hline Yes & $1.81(1.31 ; 2.51)$ & $1.72(1.34 ; 2.20)$ & $1.39(1.01 ; 1.91)$ & $1.43(1.02 ; 1.99)$ \\
\hline$p$ value for trend & 0.0003 & $<0.0001$ & 0.039 & 0.036 \\
\hline \multicolumn{5}{|l|}{ Place of residence } \\
\hline Rural areas (reference category) & 1 & 1 & 1 & 1 \\
\hline $\begin{array}{l}\text { Urban areas }<100,000 \\
\text { inhabitants }\end{array}$ & $0.82(0.72 ; 0.94)$ & $0.74(0.66 ; 0.82)$ & $0.64(0.56 ; 0.73)$ & $0.55(0.48 ; 0.64)$ \\
\hline $\begin{array}{l}\text { Urban areas } \geq 100,000 \\
\text { inhabitants }\end{array}$ & $0.56(0.37 ; 0.82)$ & $0.40(0.29 ; 0.55)$ & $0.26(0.17 ; 0.39)$ & $0.17(0.11 ; 0.27)$ \\
\hline$p$ value for trend & 0.004 & $<0.0001$ & $<0.0001$ & $<0.0001$ \\
\hline \multicolumn{5}{|l|}{ Maternal education } \\
\hline$<12$ years (reference category) & 1 & 1 & 1 & 1 \\
\hline 12 years & $0.75(0.69 ; 0.92)$ & $0.73(0.62 ; 0.86)$ & $0.66(0.54 ; 0.81)$ & $0.60(0.49 ; 0.74)$ \\
\hline$>12$ years & $0.60(0.48 ; 0.91)$ & $0.54(0.39 ; 0.75)$ & $0.44(0.29 ; 0.66)$ & $0.36(0.24 ; 0.55)$ \\
\hline$p$ value for trend & 0.002 & 0.0002 & $<0.0001$ & $<0.0001$ \\
\hline \multicolumn{5}{|l|}{ Paternal occupation } \\
\hline $\begin{array}{l}\text { Economically active } \\
\text { (reference category) }\end{array}$ & 1 & & & \\
\hline $\mathrm{UB} / \mathrm{PTJ} /$ pension/others & $1.24(1.02 ; 1.50)$ & & & \\
\hline Economically inactive & $1.53(1.04 ; 2.25)$ & & & \\
\hline$p$ value for trend & 0.029 & & & \\
\hline \multicolumn{5}{|l|}{ Income adequacy } \\
\hline $\begin{array}{l}\text { More than enough } \\
\text { (reference group) }\end{array}$ & 1 & & & \\
\hline Enough & $1.27(1.12 ; 1.73)$ & & & \\
\hline Not enough & $1.40(1.17 ; 1.94)$ & & & \\
\hline$p$ value for trend & 0.019 & & & \\
\hline \multicolumn{5}{|l|}{ Weight status-BMI $\left(\mathrm{kg} / \mathrm{m}^{2}\right)$} \\
\hline $\begin{array}{l}\text { Normal weight } \\
\text { (reference category) }\end{array}$ & 1 & 1 & 1 & 1 \\
\hline Overweight & $2.9(2.31 ; 3.64)$ & $3.12(2.63 ; 3.71)$ & $1.89(1.51 ; 2.38)$ & $2.59(2.10 ; 3.19)$ \\
\hline Obesity & $8.42(5.33 ; 12.28)$ & $\begin{array}{l}9.75(6.91 \\
\quad 13.75)\end{array}$ & $3.59(2.28 ; 5.65)$ & $\begin{array}{l}6.75(4.43 \\
10.15)\end{array}$ \\
\hline$p$ value for trend & $<0.0001$ & $<0.0001$ & $<0.0001$ & $<0.0001$ \\
\hline
\end{tabular}

relationship between parental SES and BP levels as a gradient confirms persistence of social gradients that have been observed in Poland since the 1980s in other indicators of physical health $[8,10,9]$.
Adverse consequences of low SES on BP levels and cardiovascular functions have been widely demonstrated in adults [77]. The findings of this study showed that social inequalities in BP levels manifest at adolescence. This is in 
line with the adolescent-emergent model (AEM) which states that relationships between SES and health outcomes are rather weak earlier in life but strengthen during adolescence when young people begin to be influenced by peers in their health behaviour [20, 30, 42]. Adolescence and, especially, puberty seems to be critical for the appearance of sexual dimorphism in BP which persists throughout adulthood. This finding is also in line with AEM and is most likely due to the activation of gonadal hormones with possibly a preponderant effect of testosterone involved during sexual maturation as well as acceleration in somatic growth during pubertal growth spurt $[29,81,86]$. The direct association of male sex with HTN and inverse association with pre-HTN found in our study need further analysis of data from longitudinal study.

As expected, elevated BP was independently associated with age. The likelihood of developing systolic pre-HTN and HTN increased twice with each year increase. Slightly weaker though significant association was observed between diastolic BP levels and age. Chronological age is a proxy for developmental trajectories. Its contribution varies in importance during each period prior to adulthood, so it does for BP level [18].

Not unexpectedly, our findings confirmed that parental HTN would be a major determinant of adolescent pre-HTN and HTN $[54,73]$. The contribution of genetic determinants in developing high BP is accounted for $27 \%$ of diastolic and $36 \%$ of systolic BP [11]. Environmental exposures to permissive/adverse conditions via parental SES can be targeted in order to improve community and individual health. However, SES per se does not directly impact the physical status and physiological and functional capacity of growing individuals [12] neither health outcomes and so cannot be regarded as a treatable risk factor of elevated BP. There are several causal pathways that have been hypothesized for understanding the mechanisms that transfer geographical location and social and economic environment to health disparities at the community and individual levels. Rural communities are likely to be socially disadvantaged, facing job and neighbourhood strain, having low educational attainment, limited access to culture and the Internet and, in consequence, limited health literacy, which drive them to unhealthy behaviours ultimately resulting in chronic ill health, which, in turn, coupled with limited access to health care and low education level, may limit job opportunities. This is a vicious circle. Living in urban areas typically offers opportunities for better education, employment, better accessibility to health care services and adherence to medical treatment. On the other hand, rapid urban growth may generate numerous stressors resulting from population density, pollution, noise, unemployment and poverty $[35,53]$.

In Poland, disparities in somatic growth and selected health outcomes in the young age due to place of residence is a well- known phenomenon that has been reported by numerous studies. Despite inconsistencies as to the benefits of either environment, previous studies have shown that young people from urban areas are likely to be taller, thinner and earlier maturing as well as of better general health status as compared to their peers living in rural areas [8, 34, 48, 75]. Adverse effects of rural environment and its social structure on health outcomes found in our study are consistent with the results from the CBOS August 2013 report "Profile of the rural population" [78]. According to this report, the population living in rural areas showed that the better demographic situation characterized by positive demographic balance (the net population growth rate was higher in villages than in towns and cities1.2 and 0.6 per 1000 , in 2009 , respectively) is accompanied by worse economic situation - a disposable per capita income of urban residents was twice as high as that of rural residents.

Importantly, maternal education, parental occupation, income adequacy and adolescent obesity remained significant when adjusted for all other relevant parent-related risk factors and place of residence. All these variables appear to act synergistically on adolescent BP levels via the acquisition of knowledge and skills that promote health associated with a higher level of schooling and the indirect effects of education on earnings and employment prospects [26, 87]. Wilson and colleagues, in their study on 76 black adolescents, revealed that adolescents who lived in poorer neighbourhoods had lower diastolic BPs if their mothers were more (vs. less) educated and their family had a higher (vs. lower) annual income [89]. The association between adolescent BP and maternal educational level has been demonstrated extensively [68, 83]. In our study, however, maternal occupational status interrelated with education and paternal occupation had no effect on blood pressure. Neither had family size. This finding is inconsistent with previous studies showing an independent effect of family size on offspring somatic growth [10, 48, 49]. At present study, parental educational attainment and earnings become more important for offspring BP than number of children at home.

The prevalence of elevated BP that has been reported in paediatrics recently varies substantially across countries [27, 31, 71]. The regional-wide variation in elevated BP prevalence is largely attributed to differences in geographic location, age range and methodology [39].

The overall prevalence of elevated BP was $6.6 \%$ for preHTN and $8.9 \%$ for HTN (SBP and/or DBP combined). These data indicate that the prevalence of systemic hypertension in the juvenile population in Poland has doubled over the last decade. Krzyżaniak and colleagues, in the national study of BP conducted in 2000 among Polish school children (7-19 years), reported the prevalence rate of HTN $\sim 4 \%$ [58]. Similar figures, $4.9 \%$ for HTN and $11.1 \%$ for pre-HTN, were found in a large sample study of children and adolescents, aged 7 to 19 years in the city of Lodz, Poland [76]. 
This upward trend in HTN is attributed at least in part to the rapid increase in adolescent overweight and obesity [44, 50] and the high prevalence of sedentary behaviours, physical inactivity and unhealthy dietary habits [37]. According to recent data from the national survey in Poland, the prevalence of overweight and obesity in 6-19-year-old children and adolescents is $16.4 \%$ (18.7 and $14.3 \%$, boys and girls, respectively) and underweight $-12.0 \%$ total (10.0 and $13.7 \%$, boys and girls, respectively) [44]. The findings of the present study showed similar figures: $16.8 \%$ of overweight/obese adolescents in total sample (20.1\% for boys and $14.4 \%$ for girls). Prevalence of obesity was found to be twice higher in boys $(4.2 \%)$ than in girls $(2.4 \%)$, and in rural $(2.9 \%)$ than in urban $(1.9 \%)$ residence areas. Although these figures are not top ranked among European adolescents (HBSC), predictions based on the worldwide trends suggest that it may change in the near future resulting in increasing risk of developing elevated BP and undesirable cardiovascular consequences $[27,72]$.

Brummett and colleagues revealed obesity and increased heart rate as key modifiable correlates of higher SBP and lower SES [15]. In the present study, weight status (BMI) appeared to be an independent most significant risk factor, suggesting its major role in mediating effects of parental SES on their offspring BP levels. In addition, it was found that higher parental SES was associated with lower BMI as it was claimed by Brummett and colleagues. There are many other studies identifying overweight and obesity as an independent significant factor of increased BP [21, 33, 37, 46, 80, 82].

This study is not without its limitations. A cross-sectional design makes it difficult to assess the direction and causality. This design, however, was methodologically appropriate for solving the research question, i.e., evaluating the association between BP levels (outcome variable) and exposures (parental SES, weight status) [69]. There is also a possibility that confounding factors operating earlier in life and not included to this analysis introduced bias into the study results. However, studies of the association between prenatal factors and offspring BP have yielded mixed results indicating direct or inverse associations and null results as well [7, 64]. An example of maternal smoking during pregnancy may prove that bias of present results, if any, can be neglected. Smoking during pregnancy is more common among women with low SES [47]; therefore, it was argued that the relation between smoking during pregnancy and offspring BP is due to SES confounding rather than a true intrauterine effect $[14,47]$. Another bias may be produced by errors in recall of the exposure and possible outcome. It would have been useful to have longitudinal, prospective information. The reliability of self-reported data has widely been discussed in the literature and involved in the premises of this study [40]. Finally, SES indicators do not include disposable per capita income, but we share the opinion that income adequacy reflects more adequately the families' purchasing power [88].

The strengths of this study include a population-based cohort study of healthy adolescents, the clustering structure of parental SES reflecting that of the general population (30), a multivariate approach and integration of multiple factors hypothesized as to be associated with the outcome variableadolescent arterial BP level.

\section{Conclusions}

The findings of the present study confirmed socioeconomic inequalities in blood pressure levels among adolescents. Young people living in rural areas are likely to be at a higher risk to develop elevated blood pressure than their better-off peers from urban areas.

Weight status appeared to be the strongest confounder of adolescent blood pressure level and, at the same time, a mediator between their blood pressure and parental SES. This calls for regularly performed BP assessment and monitoring in this population. Effective strategies aimed at reducing global CVD risk should focus on obesity prevention and socioeconomic health inequalities as early as at adolescence by further trying to improve living and working conditions in rural areas.

Acknowledgments The authors would like to express their sincere gratitude to the anonymous reviewers for their helpful comments and valuable suggestions on this paper.

Conflict of interest The authors declare that they have no competing interests.

Funding This work was supported by research funds 2004-2008 and co-financed by a grant from Iceland, Liechtenstein and Norway through the EEA Financial Mechanism and the Norwegian Financial Mechanism. Project PL0255 ADOPOLNOR.

Author's contributions MK was the project manager, conceived the study design, coordinated the research, conceived the paper, performed the statistical computations and drafted the manuscript; AK coordinated the medical research; and BS-W, AK, MK-W and AS made contributions to the design of the medical research, analysed and interpreted the data, and revised the content of the manuscript. All authors critically read and approved the final manuscript.

Open Access This article is distributed under the terms of the Creative Commons Attribution 4.0 International License (http:// creativecommons.org/licenses/by/4.0/), which permits unrestricted use, distribution, and reproduction in any medium, provided you give appropriate credit to the original author(s) and the source, provide a link to the Creative Commons license, and indicate if changes were made. 


\section{References}

1. A global brief of hypertension. Silent killer, global public health crisis. World Health Day 2013 (2013) Geneva, World Health Organization

2. Adams HR, Szilagyi PG, Gebhardt L, Lande MB (2010) Learning and attention problems among children with pediatric primary hypertension. Pediatrics 126(6):e1425-e1429

3. Arnett DK, Glasser SP, McVeigh G et al (2001) Blood pressure and arterial compliance in young adults: the Minnesota Children's Blood Pressure Study. Am J Hypertens 14(3):200-205

4. Bao W, Threefoot SA, Srinivasan SR, Berenson GS (1995) Essential hypertension predicted by tracking of elevated blood pressure from childhood to adulthood: The Bogalusa Heart Study. Am J Hypertens 8(7):657-665

5. Barros FC, Victora CG, Scherpbier R, Gwatkin D (2010) Socioeconomic inequities in the health and nutrition of children in low/middle income countries. Rev Saude Publica 44:1-16

6. Berenson GS, Srinivasan SR, Bao W, Newman WP III, Tracy RE, Wattigney WA (1998) Association between multiple cardiovascular risk factors and atherosclerosis in children and young adults. The Bogalusa Heart Study. N Engl J Med 338:1650-1656

7. Bergel E, Haelterman E, Belizan J, Villar J, Carroli G (2000) Perinatal factors associated with blood pressure during childhood. Am J Epidemiol 151(8):594-601

8. Bielicki T, Waliszko H (1991) Urbanization-dependent gradients in stature among Polish conscripts in 1976 and 1986. Am J Hum Biol 3:419-424

9. Bielicki T, Welon Z (1982) Growth data as indicators of social inequalities: the case of Poland. Yearb Phys Anthropol 25:153-167

10. Bielicki T, Waliszko A, Hulanicka B, Kotlarz K (1986) Social class gradients in menarcheal age in Poland. Ann Hum Biol 13(1):1-11

11. Biino G, Parati G, Concas MP, Adamo M, Angius A, Vaccargiu S, Pirastu M (2013) Environmental and genetic contribution to hypertension prevalence: data from an epidemiological survey on Sardinian genetic isolates. PLoS One 8(3):e59612

12. Bogin B (2005) Patterns of human growth 2nd edn. Cambridge University Press, Cambridge

13. Boyd GS, Koenigsberg J, Falkner B, Gidding S, Hassink S (2005) Effect of obesity and high blood pressure on plasma lipid levels in children and adolescents. Pediatrics 116(2):442-446

14. Brion MJ, Leary SD, Smith GD, Ness AR (2007) Similar associations of parental prenatal smoking suggest child blood pressure is not influenced by intrauterine effects. Hypertension 49:1422-1428

15. Brummett BH, Babyak MA, Siegler IC, Shanahan M, Harris KM, Elder GH, Williams RB (2011) Systolic blood pressure, socioeconomic status, and biobehavioral risk factors in a nationally representative US young adult sample. Hypertension 58:161-166

16. Cameron L, Williams J (2009) Is the relationship between socioeconomic status and health stronger for older children in developing countries? Demography 46:303-324

17. Carlsson AC, Wandel PE, de Faire U, Hellenius ML (2006) Risk factors associated with newly diagnosed high blood pressure in men and women. Am J Hypertens 9(5):486-491

18. Chen E (2004) Why socioeconomic status affects the health of children: a psychosocial perspective. Curr Dir Psychol Sci 13(3): $112-115$

19. Chen X, Wang Y (2008) Tracking of blood pressure from childhood to adulthood: a systematic review and meta-regression analysis. Circulation 117:3171-3180

20. Chen E, Matthews KA, Boyce WT (2002) Socioeconomic differences in children's health: how and why do these relationships change with age? Psychol Bull 128:295-329

21. Chiolero A, Cachat F, Burnier M, Paccaud F, Bovet P (2007) Prevalence of hypertension in schoolchildren based on repeated measurements and association with overweight. J Hypertens 25: 2209-2217

22. Chobanian AV, Bakris GL, Black HR et al (2003) The seventh report of the Joint National Committee on Prevention, Detection, Evaluation, and Treatment of High Blood Pressure: the JNC 7 report. JAMA 289:2560-2572

23. Cole TJ, Bellizzi MC, Flegal KM, Dietz WH (2000) Establishing a standard definition for child overweight and obesity worldwide: international survey. Br Med J 320:1240-1243

24. Cole TJ, Flegal KM, Nicholls D, Jackson AA (2007) Body mass index cut offs to define thinness in children and adolescents: international survey. Br Med J 335:194-201

25. Currie $\mathrm{C}$ et al. (eds) (2012) Social determinants of health and wellbeing among young people. Health Behaviour in School-aged Children (HBSC) study: international report from the 2009/2010 survey. Copenhagen, WHO Regional Office for Europe. Health Policy for Children and Adolescents No. 6

26. Cutler DM, Lleras-Muney A, Vogl T (2011) Socioeconomic status and health. Dimensions and mechanisms. In: Glied S and Smith PC (eds) The Oxford Handbook of Health Economics, Oxford UK: Oxford University Press

27. Danaei G, Finucane MM, Lin JK, Singh GM, Paciorek CJ, Cowan MJ, Farzadfar F, Stevens GA, Lim SS, Riley LM, Ezzati M, Global Burden of Metabolic Risk Factors of Chronic Diseases Collaborating Group (Blood Pressure) (2011) National, regional, and global trends in systolic blood pressure since 1980: systematic analysis of health examination surveys and epidemiological studies with 786 country-years and 5.4 million participants. Lancet 377(9765):568-577

28. Daniels SR, Loggie JM, Khoury P, Kimball TR (1998) Left ventricular geometry and severe left ventricular hypertrophy in children and adolescents with essential hypertension. Circulation 97:1907-1911

29. Dasgupta K, O’Loughlin J, Chen S, Karp I, Paradis G, Tremblay J et al (2006) Emergence of sex differences in prevalence of high systolic blood pressure: analysis of a longitudinal adolescent cohort. Circulation 114(24):2663-2670

30. Davey Smith G, Hart C (2002) Life-course socioeconomic and behavioural influences on cardiovascular disease mortality: the collaborative study. Am J Public Health 92:1295-1298

31. de Moraes ACF, Lacerda MB, Moreno LA, Horta BL, Carvalho HB (2014) Prevalence of high blood pressure in 122,053 adolescents: a systematic review and meta-regression. Medicine 93(27):e232

32. Del Giudice M, Angeleri R, Manera V (2009) The juvenile transition: a developmental switch point in human life history. Dev Rev 29:1-31

33. Díaz Martín JJ, Málaga Diéguez I, Argüelles Luis J, Diéguez Junquera MA, Vijande Vázquez M, Málaga Guerrero S (2005) Clustering of cardiovascular risk factors in obese offspring of parents with essential hypertension. An Pediatr 63:238-243

34. Durda M (2011) Biological status of adolescents in relation to their lifestyle behaviours and family's socioeconomic status. In: Kaczmarek M (ed) Health and well-being in adolescence. Part one physical health and subjective well-being. Bogucki Wydawnictwo Naukowe, Poznań, pp 111-137

35. Eberhardt MS, Pamuk ER (2004) The importance of place of residence: examining health in rural and nonrural areas. Am J Public Health 94(10):1682-1687

36. Eriksson JG, Forsén TJ, Kajantie E, Osmond C, Barker DJP (2007) Childhood growth and hypertension in later life. Hypertension 49: 1415-1421

37. Fairclough SJ, Boddy LM, Hackett AF, Stratton G (2009) Associations between children's socioeconomic status, weight status, and sex, with screen based sedentary behaviours and sport participation. Int J Pediatr Obes 4:299-305

38. Falkner B (2010) Hypertension in children and adolescents: epidemiology and natural history. Pediatr Nephrol 25:1219-1224 
39. Falkner B, Gidding SS, Portman R, Rosner B (2008) Blood pressure variability and classification of prehypertension and hypertension in adolescence. Pediatrics 122(2):238-242

40. Fan X, Miller BC, Park K, Winward BW, Christensen M, Grotevant HD (2006) An exploratory study about inaccuracy and invalidity in adolescent self-report surveys. Field Methods 18:223-244

41. Friel S, Marmot MG (2011) Action on the social determinants of health and health inequities goes global. Annu Rev Public Health 32:225-236

42. Galobardes B, Davey Smith G, Lynch JW (2006) Systematic review of the influence of childhood socioeconomic circumstances on risk for cardiovascular disease in adulthood. Ann Epidemiol 16:91104

43. Goodman E, McEwen BS, Huang B, Dolan LM, Adler NE (2005) Social inequalities in biomarkers of cardiovascular risk in adolescence. Psychosom Med 67:9-15

44. Grajda A, Kułaga Z, Gurzkowska B, Napieralska E, Litwin M (2011) Regional differences in the prevalence of overweight, obesity and underweight among Polish children and adolescents. Med Wieku Rozwoj 3(1):258-266

45. Grotto I, Huerta M, Sharabi Y (2008) Hypertension and socioeconomic status. Curr Opin Cardiol 23:335-339

46. Hodgkin E, Hamlin MJ, Ross JJ, Peters F (2010) Obesity, energy intake and physical activity in rural and urban New Zealand children. Rural and Remote Health 10:1336 Available: http:// www.rrh.org.au Accessed November 20, 2014

47. Högberga L, Sven Cnattingiusb S, Brian M, D'Onofrioc BM, Cecilia Lundholma C, Iliadoua AN (2012) Effects of maternal smoking during pregnancy on offspring blood pressure in late adolescence. J Hypertens 30(4):693-699

48. Hulanicka B, Kolasa E, Waliszko A (1994) Dziewczęta z Górnego Śląska. Monografie Zakładu Antropologii PAN, Wrocław, p 11

49. Jedlińska W (1985) Wpływ niektórych czynników środowiska społecznego na wysokość ciała dzieci szkolnych w Polsce. Przegl Antropol 51(1-2):15-37

50. Jodkowska M, Oblacińska A, Tabak I (2010) Overweight and obesity among adolescents in Poland: gender and regional differences. Public Health Nutr 13(10A):1688-1692

51. Kaczmarek M (2011) Conceptual frameworks and methodological tools for multidisciplinary approach to the adolescent health research. In: Kaczmarek M (ed) Health and well-being in adolescence. Part one physical health and subjective well-being. Bogucki Wydawnictwo Naukowe, Poznań, pp 19-43

52. Kaczmarek M (2012) Adolescents' health in social context. Poznań Chapter Agder Academi, Poznań. doi:10.13140/2.1.3396.5768

53. Kaczmarek M, Skrzypczak M (2011a) Health-related factors of natural and socio-economic environments in Wielkopolska Province, 2005-2009. In: Kaczmarek M (ed) Health and wellbeing in adolescence. Part one physical health and subjective well-being. Bogucki Wydawnictwo Naukowe, Poznań, pp 47-86

54. Kelishadi R, Hashemipour M, Bashardoost N (2004) Blood pressure in children of hypertensive and normotensive parents. Indian Pediatr 41:73-77

55. Kivimaki M, Lawlor DA, Smith GD, Keltikangas-Jarvinen L, Elovainio M, Vahtera J, Pulkki-Raback L, Taittonen L, Viikari JS, Raitakari OT (2006) Early socioeconomic position and blood pressure in childhood and adulthood: the Cardiovascular Risk in Young Finns Study. Hypertension 47:39-44

56. Knussmann, R (1988/1992) Anthropologie, Handbuch der vergleichenden Biologie des Menschen, Band 1. Fischer Verlag, Stuttgart pp 232-285

57. Kotchen TA, Kotchen JM, Grim CE et al (2000) Genetic determinants of hypertension identification of candidate phenotype. Hypertension 36:7-13

58. Krzyżaniak A, Stawińska-Witoszyńska B, Szilágyi-Pagowska I, Palczewska I (2003) Ciśnienie tętnicze dzieci i młodzieży województwa mazowieckiego i wielkopolskiego. Przegl Lek 60(6):81-85

59. Krzyżaniak A, Krzywińska-Wiewiorowska M, StawińskaWitoszyńska B, Kaczmarek M, Krzych $Ł$, Kowalska M et al (2009) Blood pressure references for Polish children and adolescents. Eur J Pediatr 168:1335-1342

60. Kułaga Z, Litwin M, Zajączkowska M, Wasilewska A, Tkaczyk M, Gurzkowska B, Świąder A, Różdżyńska A, Napieralska E, Grajda A, Barwicka K, Zespół badaczy OLAF (2009) Regionalne różnice parametrów antropometrycznych oraz ciśnienia tętniczego uczniów w wieku 7-18 lat. Probl Hig Epidemiol 90(1):32-41

61. Kuneš J, Zicha J (2009) The interaction of genetic and environmental factors in the etiology of hypertension. Physiol Res 58(2):S33S41

62. Kyrou I, Chrousos GP, Tsigos C (2006) Stress, visceral obesity, and metabolic complications. Ann N Y Acad Sci 1083:77-110

63. Lackland DT, Egan BM (2007) Dietary salt restriction and blood pressure in clinical trials. Curr Hypertens Rep 9:314-319

64. Law CM, Shiell AW (1996) Is blood pressure inversely related to birth weight? The strength of evidence from a systematic review of the literature. J Hypertens 14(8):935-941

65. Lawlor DA, Najman JM, Sterne J, Williams GM, Ebrahim S, Davey Smith G (2004) Associations of parental, birth, and early life characteristics with systolic blood pressure at 5 years of age: findings from the Mater-University study of pregnancy and its outcomes. Circulation 110:2417-2423

66. Lemeshow S, Hosmer DW, Klar J, Lwanga S (1990) Adequacy of sample size in health studies. Published on behalf of the World Health Organisation. Wiley

67. Lifton RP (1995) Review genetic determinants of human hypertension. Proc Natl Acad Sci U S A 92:8545-8551

68. Maldonado J, Pereira T, Fernandes R, Santos R, Carvalho M (2011) An approach of hypertension prevalence in a sample of 5381 Portuguese children and adolescents. The AVELEIRA registry. "Hypertension in Children". Blood Press 20(3):153-157

69. Mann CJ (2003) Observational research methods. Research design II: cohort, cross-sectional, and case-control studies. Emerg Med J 20:54-60

70. Martin RM, Ness AR, Gunnell D, Emmett P, Davey Smith G, ALSPAC Study Team (2004) Does breast-feeding in infancy lower blood pressure in childhood? The Avon Longitudinal Study of Parents and Children (ALSPAC). Circulation 109:1259-1266

71. May AL, Kuklina EV, Yoon PW (2012) Prevalence of cardiovascular disease risk factors among US adolescents, 1999-2008. Pediatrics 129(6):1035-1041

72. Mazur J (2010) Społeczne nierówności w zdrowiu subiektywnym młodzieży szkolnej w Polsce na tle Unii Europejskiej. Wybrane aspekty metodologiczne ilustrowane wynikami międzynarodowych badań. Wyniki badań HBSC 2010. Instytut Matki i Dziecka, Warszawa

73. Munger RG, Prineas RJ, Gomez-Marin O (1988) Persistent elevation of blood pressure among children with a family history of hypertension: the Minneapolis Children's Blood Pressure Study. J Hypertens 6:647-653

74. National High Blood Pressure Education Program Working Group of High Blood Pressure in Children Adolescents (2004) The fourth report on the diagnosis, evaluation and treatment of high blood pressure in children and adolescents. Pediatrics 114(2 Suppl 4th Report):555-576

75. Olszewska E, Łaska-Mierzejewska T (2008) Unemployment in the Polish countryside and its effect on the development and rate of maturation of rural girls. Anthropol Rev 71:33-42

76. Ostrowska-Nawarycz L, Nawarycz T (2007) Prevalence of excessive body weight and high blood pressure in children and adolescents in the city of Łódź. Kardiol Pol 65:1079-1087 
77. Pollitt RA, Rose KM, Kaufman JS (2005) Evaluating the evidence for models of life course socioeconomic factors and cardiovascular outcomes: a systematic review. BMC Public Health 5:7-19

78. Profile of the rural population. CBOS report August 2013. http:// www.cbos.pl/EN/publications/reports/2013/117_13.pdf Accessed November 10, 2014.

79. Rogacki H (ed) (2007) Geografia społeczno-gospodarcza Polski. Wydawnictwo Naukowe PWN, Warszawa

80. Salvadori M, Sontrop JM, Garg AX, Truong J, Suri RS, Mahmud FH, Macnab JJ, Clark WF (2008) Elevated blood pressure in relation to overweight and obesity among children in a rural Canadian community. Pediatrics 122:e821-e827

81. Shankar RR, Eckert GJ, Saha C, Tu W, Pratt JH (2005) The change in blood pressure during pubertal growth. J Clin Endocrinol Metab 90(1):163-167

82. Shi Y, de Groh M, Morrison H (2012) Increasing blood pressure and its associated factors in Canadian children and adolescents from the Canadian Health Measures Survey. BMC Public Health 12:388

83. Silva DA, de Lima LR, Dellagrana RA, Bacil ED, Rech CR (2013) High blood pressure in adolescents: prevalence and associated factors. Cien Saude Colet 18(11):3391-3400
84. Sorof JM, Lai D, Turner J, Poffenbarger T, Portman RJ (2004) Overweight, ethnicity, and the prevalence of hypertension in school-aged children. Pediatrics 113:475-482

85. Sourial N, Wolfson C, Zhu B, Quail J, Fletcher J, Karunananthan S et al (2010) Correspondence analysis is a useful tool to uncover the relationships among categorical variables. J Clin Epidemiol 63(6):638-646

86. Tu W, Eckert GJ, Saha C, Pratt J (2009) Synchronization of adolescent blood pressure and pubertal somatic growth. J Clin Endocrinol Metab 94(1):5019-5022

87. van den Berg G, van Eijsden M, Galindo-Garre F, Vrijkotte TGM, Gemke RJBJ (2013) Explaining socioeconomic inequalities in childhood blood pressure and prehypertension. The ABCD Study. Hypertension 61:35-41

88. Wilkinson GR (1997) Socioeconomic determinants of health: health inequalities: relative or absolute material standards? BMJ 314:591-595

89. Wilson DK, Kliewer W, Plybon L, Sica DA (2000) Socioeconomic status and blood pressure reactivity in healthy black adolescents. Hypertension 35(2):496-500

90. World Medical Association Declaration of Helsinki. Ethical principles for medical research involving human subjects (2001) Bull World Health Organ 79(4):373-374 